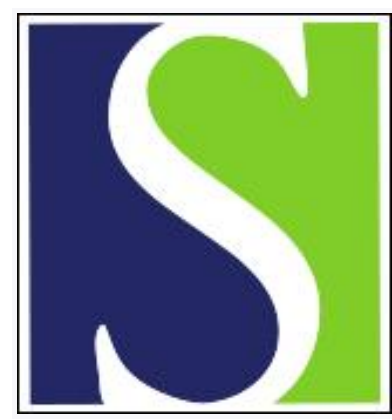

Scand J Work Environ Health 2015;41(2):218

https://doi.org/10.5271/sjweh.3474

Published online: 16 Dec 2014, Issue date: 01 Mar 2015

Author response to letter. Ref: Madsen et al. “Unnecessary work tasks and mental health: a prospective analysis of Danish human service workers"

by Madsen IEH, Rugulies $R$

Affiliation: National Research Centre for the Working Environment, Lerso Parkalle 105, DK-2100 Copenhagen, Denmark. inm@nrcwe.dk

Refers to the following texts of the Journal: $2015 ; 41(2): 216-217$ 2014;40(6):631-638

Key terms: human service worker; letter to the editor; mental health; unnecessary work task

This article in PubMed: www.ncbi.nlm.nih.gov/pubmed/25514578 


\section{Author response to letter. Ref: Madsen et al. "Unnecessary work tasks and mental health: a prospective analysis of Danish human service workers"}

We read with interest the letter from Drs DurandMoreau, Loddé, and Dewitte (1) regarding our article on unnecessary work tasks and mental health (2). The authors argue that: (i) the article is flawed by an imprecise one-item exposure measurement, (ii) the results may be affected by reverse causality, and (iii) ultimately the elimination of unnecessary work tasks may increase "psychic suffering". We would like to take this opportunity to address their concerns.

We acknowledge, as we did in the article itself, that measuring unnecessary work tasks using only one item is less than ideal and could have increased measurement error in our analyses. The item we used to measure unnecessary work tasks assesses the employee's overall evaluation regarding the extent to which they must conduct work tasks that they, for whatever reason, deem unnecessary. We are unconvinced by the claim by Drs Durand-Moreau, Loddé, and Dewitte that this phenomenon is somehow unrelated to Semmer's definition of unnecessary tasks $(3,4)$, regardless of the sense-making processes underlying an individual employee's evaluation of a particular work task as unnecessary.

Regarding the issue of reverse causality, the analyses were longitudinal and the effect estimates were adjusted for the baseline mental health level of the participants. Consequently, we examined changes in mental health over time, and our results cannot be explained by poorer mental health making workers think "that what they're doing is useless" as claimed in the commentary. Although causal inference is always a delicate issue when applying observational research methods, the adjustment for baseline mental health should account for reverse causality at least.

Drs Durand-Moreau, Loddé, and Dewitte question that our findings suggest that the elimination of unnecessary work tasks may be beneficial to employee mental health. Instead they propose that unnecessary work tasks may be conducive to mental health because "some tasks may seem unnecessary or bothersome, but may correspond to work periods that allow for temporary rest". We find this suggestion curious and are not aware of any empirical studies to support this claim. Consequently, we encourage the authors of the commentary to test their hypothesis empirically. Any such empirical evidence would be a welcome advancement to the scientific knowledge concerning the mental health consequences of unnecessary work tasks. As the results of our study do not indicate that unnecessary work tasks could be beneficial to mental health, but indeed that they could be harmful, we find no reason to modify the conclusions of our article.

\section{References}

1. Durand-Moreau Q, Loddé B, Dewitte J-D. Ref: Madsen et al. "Unnecessary work tasks and mental health: a prospective analysis of Danish human service workers". Scand J Work Environ Health. 2015;41(2):216-217. http://dx.doi. org/10.5271/sjweh.3473.

2. Madsen IEH, Tripathi M, Borritz M, Rugulies R, Unnecessary work tasks and mental health: a prospective analysis of Danish human service workers, Scand J Work Environ Health. 2014;40(6):631-8. http://dx.doi.org/10.5271/sjweh.3453.

3. Semmer NK, Tschan F, Meier LL, Facchin S, Jacobshagen N, Illegitimate tasks and counterproductive work behavior, Appl Psychol. 2010;59:70-96. http://dx.doi.org/10.1111/j.14640597.2009.00416.x.

4. Durand MJ, Vézina N, Baril R, Loisel P, Richard MC, Ngomo $\mathrm{S}$, Margin of manoeuvre indicators in the workplace during the rehabilitation process: a qualitative analysis, J Occup Rehab. 2009;19:194-202. http://dx.doi.org/10.1007/s10926-0099173-4.

Ida EH Madsen, PhD, ${ }^{1}$ Reiner Rugulies, $P h D^{1,2,3}$ on behalf of all the authors

1 National Research Centre for the Working Environment, Copenhagen, Denmark.

2 Department of Public Health, University of Copenhagen, Copenhagen, Denmark.

3 Department of Psychology, University of Copenhagen, Copenhagen, Denmark.

Correspondence to: Ida E H Madsen, National Research Centre for the Working Environment, Lerso Parkalle 105, DK-2100 Copenhagen, Denmark. [E-mail: ihm@nrcwe.dk] 